\title{
Development and validation of the Mini Asthma Quality of Life Questionnaire
}

\author{
E.F. Juniper*, G.H. Guyatt*, F.M. Cox ${ }^{+}$, P.J. Ferrie*, D.R. King*
}

Development and validation of the Mini Asthma Quality of Life Questionnaire. E.F. Juniper, G.H. Guyatt, F.M. Cox, P.J. Ferrie, D.R. King. (C)ERS Journals Ltd 1999.

ABSTRACT: The 32-item Asthma Quality of Life Questionnaire (AQLQ) has shown good responsiveness, reliability and construct validity; properties that are essential for use in clinical trials, clinical practice and surveys. However, to meet the needs of large clinical trials and long-term monitoring, where efficiency may take precedent over precision of measurement, the 15 -item self-administered MiniAQLQ has been developed.

The MiniAQLQ was tested in a 9-week observational study of 40 adults with symptomatic asthma. Patients completed the MiniAQLQ, the AQLQ, the Short Form (SF)-36, the Asthma Control Questionnaire and spirometry at baseline, 1, 5 and 9 weeks.

In patients whose asthma was stable between clinic visits, reliability was very acceptable for the MiniAQLQ (intraclass correlation coefficient $($ ICC) $=0.83$ ), but not quite as good as for the AQLQ (ICC=0.95). Similarly, responsiveness in the MiniAQLQ ( $p=0.0007)$ was good but not quite so good as for the AQLQ $(p<0.0001)$. Construct validity (correlation with other indices of health status) was strong for both the MiniAQLQ and the AQLQ. Criterion validity showed that there was no bias between the instruments $(p=0.61)$ and the correlation between them was high $(r=0.90)$.

The Mini Asthma Quality of Life Questionnaire has good measurement properties but they are not quite as strong as those of the original Asthma Quality of Life Questionnaire. The choice of questionnaire should depend on the task at hand. Eur Respir J 1999; 14: 32-38.
*Dept of Clinical Epidemiology and Biostatistics, McMaster University, Hamilton, Ontario, Canada. ${ }^{+}$Glaxo Wellcome Inc., Research Triangle Park, North Carolina, USA.

Correspondence: E.F. Juniper

Dept of Clinical Epidemiology and Biostatistics

McMaster University Medical Centre

1200 Main Street West

Hamilton

Ontario

L8N 3 Z5

Canada

Fax: 9055770017

Keywords: Asthma

quality of life

questionnaire

Received: August 141998

Accepted after revision December 201998

Supported by a grant from GlaxoWellcome Inc.
The original 32-item Asthma Quality of Life Questionnaire (AQLQ) [1] was developed to measure the functional impairments that are most troublesome to adult patients with asthma. It has four domains: symptoms (12 items), activity limitation (11 items), emotional function (5 items), and environmental stimuli (4 items). Five independent validation studies have shown that it has strong evaluative and discriminative measurement properties [26]. However, for greater efficiency in large clinical trials, group patient monitoring and large surveys, where precision of measurement is less important, a shorter and simpler questionnaire is needed. In response to this need, the Mini Asthma Quality of Life Questionnaire (MiniAQLQ) has been developed and compared to the original AQLQ in terms of both absolute score and measurement properties.

\section{Subjects and methods}

\section{Development of the MiniAQLQ}

Instrument specification. The aim was to create an instrument that would measure the same construct and meet the same specifications as the original AQLQ [1] which were: 1) include the physical and emotional impairments that adults with asthma consider most important; 2) reliable, i.e., reproducible when the clinical state is stable and be able to discriminate between patients with different levels of impairment; 3) responsive, i.e., sensitive to small but clinically important within-subject changes; 4) valid, i.e., measures asthma-specific quality of life; and 5) short and easy to complete.

In addition, it was specified that the MiniAQLQ should maintain, as much as possible, the measurement properties of the original AQLQ and each of its four domains. It was specified that: the MiniAQLQ should maintain a similar proportion of items in each of the four domains, the minimum number of items in each domain should be three, all activities should be generic, and it should be structured for self-administration. To meet these criteria, the following format was selected: symptoms, 5 items; activity limitation, 4 items (all generic); emotional function, 3 items; and environmental stimuli, 3 items.

Item selection. A number of methods have been proposed for shortening questionnaires [7]. A composite approach was used in this study to ensure that the specifications were met. Firstly, redundancy was removed by combining items. Item-item correlations were examined in four data sets: the original development study $(n=150)$ [1]; the authors' validation study $(n=39)$ [2]; the Canadian salmeterol/salbutamol study $(\mathrm{n}=140)$ [8]; and a USA salmeterol/salbutamol study $(n=2,073)$. If the item-item 
correlations were greater than $\mathrm{r}=0.7$ in three of the four studies, six clinicians reviewed each pair to determine whether they were sufficiently similar in concept to combine into a single item. Twelve items were combined in this manner thus reducing the questionnaire from 32 to 26 items (Appendix 1).

Secondly, the items in the activity domain were standardized. For the MiniAQLQ, four of the five generic activities from the standardized version of the AQLQ (AQLQ(S)) have been used (strenuous activities, moderate activities, social activities and work-related activities) [9]. It has been shown that these generic activities cover the majority of activities in which asthma patients experience limitations [9]. The fifth generic activity in the AQLQ(S), "sleep", has been omitted from the MiniAQLQ because sleep problems are already included in the symptom domain. Four of the AQLQ activity items (avoiding cigarette smoke, dust, weather and strong smells) had already been combined with items in the environmental domain (see above and Appendix 1) and the final two activity questions of the AQLQ, concerning range and overall activities (questions 31 and 32), are very general and are well covered by the four generic items. Reducing the activity domain in this way, decreased the overall number of items in the questionnaire to 23 .

For the final step, in keeping with the first specification and using the impact method for item selection [10], the items in the AQLQ which are the least important to the majority of patients with asthma were removed. Using data from the original item reduction phase of the AQLQ [1], items with the lowest impact (frequency $\times$ importance) were removed until the pre-specified number of items required in each domain was reached. The 15-item MiniAQLQ is self-administered and patients are asked to recall their experiences during the previous two weeks and respond to each question on a 7-point scale (Appendix 2).

Pre-testing of the MiniAQLQ. To ensure ease of completion and accuracy of understanding, nine adults with symptomatic asthma, representing a range of asthma severity, academic achievement, sex and age, completed the MiniAQLQ without verbal instructions. Minor wording changes were required and the modified questionnaire was tested on a further five patients, all of whom completed it with ease. No further changes were needed.

\section{Validation}

Subjects. Forty adults (aged 18-65 yrs) with symptomatic asthma were enrolled from patients who had participated in previous studies or who responded to notices in the local media. Patients were excluded if they had evidence of fixed airway obstruction (forced expiratory volume in one second (FEV1) postbronchodilator $<60 \%$ predicted) or other illness that might have an impact on health-related quality of life. All participants communicated in English and were able to make reliable measurements of peak expiratory flow (PEF). They all signed a consent that had been approved by the McMaster University Faculty of Health Sciences Ethics Committee.

Study design. In this 9-week, observational study, patients were assessed at baseline and after 1, 5 and 9 weeks. For one week before each follow-up clinic visit, patients completed a daily diary. At each visit, tests, questionnaires and patient discussions were completed in the following order: MiniAQLQ; prebronchodilator spirometry; Medical Outcome Study (MOS) Short Form (SF)-36; Asthma Control Questionnaire (ACQ); review of diary (symptoms and $\beta_{2}$-agonist use); evaluation of PEF and inhaler techniques; assessment of asthma control; discussion on future medication use; postbronchodilator spirometry; patient instruction; booking of next appointment; and self-administered version of the AQLQ.

Patients, whose asthma was adequately controlled, continued on their established asthma medications throughout the study. Patients, whose asthma was not adequately controlled at week 1 and/or week 5 , were advised to increase their medication in the manner recommended by their asthma physician.

Outcome measures. Asthma Control Questionnaire. Ninety-two asthma clinicians from around the world identified the symptoms that are most important in determining clinical asthma control. The ACQ [11] contains the five top scoring symptoms, a question about $\beta_{2}$-agonist use and another about FEV $1 \%$ pred (total of seven questions). Patients are asked to score how their asthma has been during the previous 7 days and to respond to each question on a 7-point scale $(0=$ no impairment, $6=$ maximum impairment). The ACQ has been fully validated and shows strong measurement properties.

Daily diary. Each morning patients recorded the best prebronchodilator PEF of three blows and the amount of short-acting $\beta_{2}$-agonist used in the previous $24 \mathrm{~h}$.

Medical Outcomes Survey Short Form 36. This 36-item generic health status instrument [12] provides scores for physical and mental health. In asthma, it has good internal consistency and cross-sectional validity [13].

Statistical analysis. The first objective was to compare the data from the MiniAQLQ with those from the original AQLQ (criterion validity). The concordance between the two instruments was examined with an intraclass correlation coefficient (ICC), bias with a paired Student's t-test and closeness of association with a Pearson correlation coefficient.

The second part of the analysis was to compare the measurement properties (reliability, responsiveness and both cross-sectional and longitudinal construct validity) [14] of the two instruments. This required defining a group of patients whose asthma remained stable between consecutive clinic visits (weeks 1-5 and 5-9) (group A) and a group of patients whose asthma changed between these visits (group B). The categorization was performed using the ACQ data in which a change in score of $\leq 0.5$ on the 7-point scale can be considered clinically important [11]. Patients who either improved or deteriorated by a score $\geq 0.5$ were placed in Group B. All other patients were placed in group A.

The reliability of the instruments was determined from patients in group A. If a patient contributed more than one data point to this category, a single point was selected blindly using a random number generator. Test-retest reliability has been estimated as the within-subject standard 
Table 1. - Patient characteristics in the validation study

\begin{tabular}{lc}
\hline Subjects $n$ & 40 \\
Age yrs & $38.4 \pm 11.2$ \\
Sex M/F & $12 / 28$ \\
Current asthma medications & \\
No medications & 1 \\
Short-acting $\beta_{2}$-agonist alone & 7 \\
Short-acting $\beta_{2}$-agonist + inhaled steroid & 29 \\
Short- and long-acting $\beta_{2}$-agonist + inhaled & 3 \\
$\quad$ steroid & \\
FEV1\% pred prebronchodilator & $77.8 \pm 20.2$ \\
\hline
\end{tabular}

Data are presented as mean \pm SD or numbers. M: male; F: female; FEV1: forced expiratory volume in one second.

deviation and related to the total standard deviation as an ICC. This statistic also provides evidence of the instrument's ability to discriminate between patients of different levels of impairment [14].

The responsiveness of the instruments was determined in three ways. Firstly, for patients in group B, it was determined whether the instruments could detect changes in patients who changed using a paired Student's t-test. Secondly, it was determined whether the instrument could detect differences between patients in groups A and B using an unpaired Student's t-test. Thirdly, the responsiveness index $(\Delta / \Delta \mathrm{SD}$, where $\Delta=$ change in score between visits) was calculated [15]. The difference in responsiveness indices between instruments was tested using a paired Student's t-test. Some patients experienced a change in their asthma during both study periods and therefore contributed two observations to group B. To ensure that this did not result in an overestimate of the precision of responsiveness, the variance was inflated to take into account within-subject correlations by the quantity $1+(n-1) \rho$, where $\rho$ is the ICC of the change scores and $n=2$ (the number of observations per subject).

Five independent validation studies have provided evidence that the AQLQ measures asthma-specific quality of life [2-6]. It was reasoned that if the MiniAQLQ also measures the same construct, it should not only correlate closely with the AQLQ, it should show similar correlations with other measures of asthma and generic health status. Both cross-sectional and longitudinal construct validity was examined in this way.

\section{Results}

Thirty-nine patients completed the study; one patient failed to return for the final visit. Demographic data are shown in table 1 .
Table 3. - Reliability of the Asthma Quality of Life Questionnaire (AQLQ) and the MiniAQLQ $(n=35)$

\begin{tabular}{lccc}
\hline Instrument & $\begin{array}{c}\text { Within-subject } \\
\text { SD }\end{array}$ & $\begin{array}{c}\text { Between-subject } \\
\text { SD }\end{array}$ & ICC \\
\hline AQLQ overall & 0.18 & 0.80 & 0.95 \\
Symptoms & 0.18 & 0.82 & 0.95 \\
Environment & 0.53 & 1.14 & 0.82 \\
Emotions & 0.29 & 1.17 & 0.94 \\
Activities & 0.31 & 0.75 & 0.85 \\
MiniAQLQ overall & 0.34 & 0.76 & 0.83 \\
Symptoms & 0.36 & 0.78 & 0.82 \\
Environment & 0.60 & 1.15 & 0.79 \\
Emotions & 0.55 & 1.14 & 0.81 \\
Activities & 0.40 & 0.63 & 0.72 \\
\hline
\end{tabular}

ICC: intraclass correlation coefficient.

\section{Comparison of instruments}

For overall quality of life and the symptom and emotional function domains, there was no evidence of any difference in scores between the MiniAQLQ and the AQLQ (table 2). For the environmental domain, MiniAQLQ scores were slightly, but significantly lower (worse) than AQLQ scores. For the activity domain, AQLQ scores were lower (worse) than MiniAQLQ scores. Correlations between the two instruments were strong $(r>0.80)$ for the overall score and the symptom, emotional function and environmental domains, but only moderately strong for the activity domain $(r=0.63)$.

\section{Measurement properties}

Reliability. Thirty-five patients remained stable between two consecutive clinic visits (either weeks $1-5$ or 5-9) and thus contributed data to the reliability analysis (group A). The within-subject standard deviations and ICCs for overall scores and individual domains are shown in table 3 . In summary, the within-subject standard deviations for the MiniAQLQ were consistently larger than for the AQLQ. The resultant ICCs for the MiniAQLQ were good, but consistently lower than for the AQLQ.

Responsiveness. Twenty-six patients contributed 35 observations to the changed group (group B), and 35 patients contributed 44 observations to the stable group (group A). Table 4 shows the responsiveness of the two instruments. Although both instruments were able to detect the changes that occurred in group B, the AQLQ was consistently better at detecting the differences between groups $\mathrm{A}$ and $\mathrm{B}$. The responsiveness index for the MiniAQLQ (0.97) was lower than for the AQLQ (1.35), but the difference did not reach significance $(p=0.14)$.

Table 2. - Asthma Quality of Life Questionnaire (AQLQ) and MiniAQLQ at the end of week $1(n=40)$

\begin{tabular}{lccccccc}
\hline Domain & AQLQ* $^{*}$ & MiniAQLQ* $^{*}$ & $\begin{array}{c}\text { Concordance }^{+} \\
\text {ICC }\end{array}$ & $\begin{array}{c}\text { Difference }^{+} \\
\text {p-value }\end{array}$ & $\begin{array}{c}\text { Correlation }^{+} \\
\text {Pearson } r\end{array}$ & $\begin{array}{c}\text { AQLQ } \\
\text { Cronbach's alpha }\end{array}$ & $\begin{array}{c}\text { MiniAQLQ } \\
\text { Cronbach's alpha }\end{array}$ \\
\hline Overall & $5.4 \pm 0.8$ & $5.4 \pm 0.9$ & 0.90 & 0.61 & 0.90 & 0.82 & 0.80 \\
Symptoms & $5.3 \pm 0.8$ & $5.3 \pm 0.9$ & 0.84 & 0.57 & 0.84 & 0.87 & 0.84 \\
Environment & $5.3 \pm 1.4$ & $4.9 \pm 1.4$ & 0.78 & 0.006 & 0.81 & 0.90 & 0.89 \\
Emotions & $5.4 \pm 1.3$ & $5.4 \pm 1.3$ & 0.90 & 0.68 & 0.90 & 0.88 & 0.86 \\
Activities & $5.7 \pm 0.9$ & $6.0 \pm 0.9$ & 0.58 & 0.01 & 0.63 & 0.85 & 0.86 \\
\hline
\end{tabular}

ICC: intraclass correlation coefficient. *: measured on 7-point scale where 7=no impairment and $1=$ maximum impairment (mean \pm SD); ${ }^{+}$: evaluated between AQLQ and MiniAQLQ. 
Table 4. - Responsiveness: the change in score between consecutive visits

\begin{tabular}{lrlc}
\hline Instrument & Group A & \multicolumn{1}{c}{ Group B } & p-value \\
\hline AQLQ overall & $0.08 \pm 0.37$ & $0.89 \pm 0.66^{* * *}$ & $<0.0001$ \\
Symptoms & $0.11 \pm 0.54$ & $1.27 \pm 0.78^{* * *}$ & $<0.0001$ \\
Environment & $-0.01 \pm 0.64$ & $0.45 \pm 0.81^{* *}$ & 0.007 \\
Emotions & $0.05 \pm 0.65$ & $0.88 \pm 1.06^{* * *}$ & $<0.0001$ \\
Activities & $0.10 \pm 0.40$ & $0.61 \pm 0.58^{* * *}$ & $<0.0001$ \\
MiniAQLQ overall & $0.15 \pm 0.94$ & $0.86 \pm 0.73^{* * *}$ & 0.0007 \\
Symptoms & $0.17 \pm 0.99$ & $1.28 \pm 0.82^{* * *}$ & $<0.0001$ \\
Environment & $0.10 \pm 1.05$ & $0.42 \pm 0.77^{* *}$ & 0.15 \\
Emotions & $0.33 \pm 1.05$ & $0.77 \pm 1.28^{* *}$ & 0.10 \\
Activities & $0.08 \pm 0.99$ & $0.73 \pm 0.77^{* * *}$ & 0.0027
\end{tabular}

Data are presented as mean \pm SD. Group A: subjects whose asthma remained stable between visits $(\mathrm{n}=44)$; Group $\mathrm{B}$ : subjects whose asthma changed between visits $(n=35)$ AQLQ: Asthma Quality of Life Questionnaire. ${ }^{+}$: difference between groups $\mathrm{A}$ and $\mathrm{B}$, unpaired t-test. **: $\mathrm{p}<0.01 ; * * *$ : $\mathrm{p}<0.001$, within subject changes from a paired t-test.

Construct validity. Cross-sectional correlations for the AQLQ and the MiniAQLQ are sufficiently similar (table 5) to allow confidence that, when used as a discriminative instrument, the MiniAQLQ is measuring asthmaspecific quality of life. However, in the longitudinal correlations, the MiniAQLQ tended to correlate less well with the Asthma Control Questionnaire, $\beta_{2}$-agonist use and SF-36 physical than did the AQLQ (table 6), suggesting that the MiniAQLQ is not quite as good at measuring change in asthma quality of life as the AQLQ.

\section{Discussion}

This study has shown that the MiniAQLQ measures the same construct as the original AQLQ, but the precision of measurement is not quite as good. The approximate doubling of the within-subject standard deviation (table 3) shows that the MiniAQLQ has less power than the AQLQ and will require larger sample sizes to achieve statistical significance. Nevertheless, by any normal standards of instrument validation, the evaluative and discriminative measurement properties of the MiniAQLQ are strong and it can be used with confidence in both longitudinal (clinical trials) and cross-sectional (surveys) studies.
Scores for both the activity and environmental stimuli domain of the AQLQ and the MiniAQLQ were significantly different, but in neither case were they large enough to be considered clinically important [16]. In the original AQLQ, patients select the five activities in which they have been most bothered by their asthma and these stay constant throughout the study. The generic activities of the MiniAQLQ may not capture all these activities and one or more of the generic activities may be irrelevant giving rise to a risk of a ceiling effect (e.g. a patient who never does strenuous activities).

In contrast, the environmental scores were lower (worse) for the MiniAQLQ than the AQLQ. In the AQLQ, patients only score how troubled they have been on exposure to environmental stimuli whereas in the MiniAQLQ, they score the problems that they have experienced as a result of both exposure and avoidance, the avoidance component having previously been in the activity domain.

Many of the methods that have been proposed for questionnaire shortening depend on quite complex statistical methods, such as factor analysis [7]. However, most of these techniques are inappropriate for disease-specific quality-of-life questionnaires [17]. The impact method that was used in this study ensures that all the problems that are important to patients are included in the shortened questionnaire, irrespective of their mathematical relationships with each other [10].

The finding that overall scores (table 2) were very similar for the MiniAQLQ and the AQLQ implies that investigators can compare burden of illness across different cross-sectional studies and compare baseline quality-of-life scores in clinical trials. In addition, the observation that changes in overall scores were similar for the AQLQ and the MiniAQLQ (table 4) suggests that results from clinical trials will also be comparable.

Patients completed the MiniAQLQ and the AQLQ at the same clinic visit and completion of the MiniAQLQ may have influenced responses to the AQLQ. However, to compare the measurement properties, it was necessary for patients to complete the questionnaires on the same day. To minimize confounding, completion of the MiniAQLQ and AQLQ was separated as much as possible by placing the MiniAQLQ at the beginning and the AQLQ at the end of each clinic visit. Approximately $1 \mathrm{~h}$ elapsed between completion of the two questionnaires during which time patients were occupied in a range of other activities.

Table 5. - Cross-sectional validity (Pearson correlation coefficients)

\begin{tabular}{|c|c|c|c|c|c|c|}
\hline Instrument & $\begin{array}{l}\text { Asthma Control } \\
\text { Questionnaire }\end{array}$ & PEF & $\begin{array}{l}\Delta \mathrm{FEV} 1 \\
\% \text { pred }\end{array}$ & $\begin{array}{c}\beta_{2} \text {-agonist } \\
\text { use }\end{array}$ & $\begin{array}{l}\text { SF-36 } \\
\text { physical }\end{array}$ & $\begin{array}{l}\text { SF-36 } \\
\text { mental }\end{array}$ \\
\hline AQLQ overall & $0.64^{+}$ & $0.20^{\S}$ & $0.18^{\S}$ & 0.03 & $0.53^{\#}$ & 0.48 \\
\hline Symptoms & $0.72^{+}$ & $0.24^{\S}$ & $0.08^{\S}$ & 0.18 & $0.34^{\#}$ & $0.42^{\#}$ \\
\hline Environment & $0.28^{\#}$ & $0.11^{\S}$ & $0.33^{\S}$ & 0.01 & $0.54^{\#}$ & $0.14^{\#}$ \\
\hline Emotions & $0.57^{\#}$ & $0.14^{\S}$ & $0.06^{\S}$ & 0.12 & $0.37^{\#}$ & $0.55^{\#}$ \\
\hline Activities & $0.43^{\#}$ & $0.13^{\S}$ & $0.21^{\S}$ & -0.19 & $0.54^{+}$ & $0.44^{\#}$ \\
\hline MiniAQLQ overall & $0.69^{+}$ & $0.25^{\S}$ & $0.06^{\S}$ & 0.02 & $0.53^{\#}$ & 0.55 \\
\hline Symptoms & $0.72^{+}$ & $0.28^{\S}$ & $0.01^{\S}$ & 0.09 & $0.37^{\#}$ & $0.53^{\#}$ \\
\hline Environment & $0.34^{\#}$ & $0.13^{\S}$ & $0.16^{\S}$ & -0.09 & $0.57^{\#}$ & $0.27^{\#}$ \\
\hline Emotions & $0.61^{\#}$ & $0.20^{\S}$ & $0.09^{\S}$ & 0.05 & $0.24^{\#}$ & $0.54^{\#}$ \\
\hline Activities & $0.52^{\#}$ & $0.20^{\S}$ & $-0.07^{\S}$ & 0.00 & $0.55^{+}$ & $0.44^{\#}$ \\
\hline
\end{tabular}

AQLQ: Asthma Quality of Life Questionnaire; PEF: peak expiratory flow; FEV1: forced expiratory volume in one second; SF-36: Short Form 36. Expected correlations based on previous observations $[2-5] .^{+}: \mathrm{r}>0.6{ }^{\#}: \mathrm{r}=0.4-0.6{ }^{\circ}{ }^{\S}: \mathrm{r}<0.2$. Where $\mathrm{r}$-values are not indicated the data were not available. All $\mathrm{r}$-values $\geq 0.33$ are statistically significant $(\mathrm{p}<0.05)$. 
Table 6. - Longitudinal validity (Pearson correlation coefficients)

\begin{tabular}{|c|c|c|c|c|c|c|}
\hline Instrument & $\begin{array}{c}\Delta \text { Asthma Control } \\
\text { Questionnaire }\end{array}$ & $\triangle \mathrm{PEF}$ & $\begin{array}{l}\triangle \mathrm{FEV} 1 \\
\% \text { pred }\end{array}$ & $\begin{array}{l}\Delta \beta_{2} \text {-agonist } \\
\text { use }\end{array}$ & $\begin{array}{r}\Delta S F-36 \\
\text { physical }\end{array}$ & $\begin{array}{l}\Delta \text { SF-36 } \\
\text { mental }\end{array}$ \\
\hline$\triangle \mathrm{AQLQ}$ overall & $0.84^{+}$ & $0.45^{\#}$ & $0.23^{*}$ & $0.52^{\#}$ & 0.42 & 0.05 \\
\hline$\Delta$ Symptoms & $0.86^{+}$ & $0.48^{\#}$ & $0.25^{\star}$ & $0.57^{\#}$ & $0.46^{\star}$ & $0.05^{\ddagger}$ \\
\hline$\Delta$ Environment & $0.41^{\#}$ & $0.16^{+}$ & $0.08^{*}$ & $0.26^{+}$ & $0.15^{\star}$ & $-0.06^{\S}$ \\
\hline$\Delta$ Emotions & $0.63^{+}$ & 0.28 & $0.16^{*}$ & $0.33^{+}$ & $0.33^{*}$ & $0.08^{+}$ \\
\hline$\Delta$ Activities & $0.74^{\#}$ & $0.42^{\dagger}$ & 0.20 & $0.43^{\#}$ & $0.32^{*}$ & $0.07^{\S}$ \\
\hline$\Delta$ MiniAQLQ overall & $0.69^{+}$ & $0.44^{\#}$ & $0.26^{\star}$ & $0.40^{\#}$ & $0.22^{*}$ & 0.16 \\
\hline$\Delta$ Symptoms & $0.79^{+}$ & $0.50^{\#}$ & $0.31^{*}$ & $0.49^{\#}$ & 0.29 & $0.13^{+}$ \\
\hline$\Delta$ Environment & $0.39^{\#}$ & $0.32^{*}$ & $0.06^{\star}$ & $0.21^{+}$ & $0.03 *$ & $0.04^{\S}$ \\
\hline$\Delta$ Emotions & $0.51^{+}$ & 0.24 & $0.25^{\star}$ & $0.17^{*}$ & $0.08^{*}$ & 0.24 \\
\hline$\Delta$ Activities & $0.56^{\#}$ & $0.41^{+}$ & $0.18^{\ddagger}$ & $0.43^{\#}$ & 0.27 & $0.12^{\S}$ \\
\hline
\end{tabular}

For definitions see footnote to table 5. Expected correlations based on previous observations $[2,3,7] .^{+}: r>0.6 ;{ }^{*}: r=0.4-0.6 ;{ }^{*}: r=0.2-$ $0.4{ }^{\S}: \mathrm{r}<0.2$. Where $\mathrm{r}$-values are not indicated the data was not available. All r-values $\geq 0.23$ are statistically significant $(\mathrm{p}<0.05)$.

A limitation of this study is the relatively small and possibly homogeneous sample. However, all five AQLQ validations studies had very similar sample sizes, represented a wide range of asthma severity and socioeconomic status, and still yielded consistent results [2-6]. In addition, results from a large number of clinical trials have upheld these validity observations. Although the authors endeavoured to enrol patients with a wide range of asthma severity, academic achievement and socioeconomic status, most were Caucasians with moderately well controlled asthma. Testing the MiniAQLQ in other settings will increase confidence in the general applicability of the results.

Disease-specific quality-of-life questionnaires are designed to measure the problems that are most important to the majority of patients with this condition, but patients are heterogeneous in their experiences and priorities and no questionnaire can cover all of the problems experienced by all patients. The more that the number of items in a questionnaire is reduced, the more likely it is that individual patient problems will be omitted and the instrument will lose content validity. The patient-specific items in the Asthma Quality of Life Questionnaire are particularly well suited for helping clinicians identify the activities that are most important to an individual patient and the wider range of questions is more likely to highlight specific patient problems. The Mini Asthma Quality of Life Questionnaire can certainly be used with confidence in large clinical trials and surveys, but further studies are needed to evaluate the utility of the Mini Asthma Quality of Life Questionnaire in clinical practice.

Appendix 1: Item selection for the Mini Asthma Quality of Life Questionnaire (MiniAQLQ)

\begin{tabular}{|c|c|c|}
\hline Question No. & Original AQLQ & MiniAQLQ \\
\hline 1 & Individualized activity 1 & Included in 4 standardized activities \\
\hline 2 & Individualized activity 2 & Included in 4 standardized activities \\
\hline 3 & Individualized activity 3 & Included in 4 standardized activities \\
\hline 4 & Individualized activity 4 & Included in 4 standardized activities \\
\hline 5 & Individualized activity 5 & Included in 4 standardized activities \\
\hline 6 & Chest tightness & Combined with question 14 (chest heaviness) \\
\hline 7 & Concerned re asthma & Included \\
\hline 8 & Short of breath & Included \\
\hline 9 & Exposure to cigarette smoke & Combined with question 11 (avoid cigarette smoke) \\
\hline 10 & Wheeze & Included \\
\hline 11 & Avoid cigarette smoke & Combined with question 9 \\
\hline 12 & Cough & Included \\
\hline 13 & Frustrated & Included \\
\hline 14 & Chest heaviness & Combined with question 6 \\
\hline 15 & Concerned re-medications & Omitted (low impact score) \\
\hline 16 & Clear throat & Omitted (low impact score) \\
\hline 17 & Exposure to dust & Combined with question 19 (avoid dust) \\
\hline 18 & Difficulty breathing out & Omitted (low impact score) \\
\hline 19 & Avoid dust & Combined with question 17 \\
\hline 20 & Wake in a.m. with symptoms & Omitted (low impact score) \\
\hline 21 & Afraid of not having medications & Included \\
\hline 22 & Heavy breathing & Omitted (low impact score) \\
\hline 23 & Exposure to weather/air pollution & Combined with question 25 (avoid weather/air pollution) \\
\hline 24 & Woken at night by asthma & Combined with question 29 (lack of a good night's sleep) \\
\hline 25 & Avoid weather/air pollution & Combined with question 23 \\
\hline 26 & Exposure to strong smells & Combined with question 28 , then omitted (low impact score) \\
\hline 27 & Afraid of getting out of breath & Omitted (low impact score) \\
\hline 28 & Avoid strong smells & Combined with question 26 , then omitted (low impact score) \\
\hline 29 & Lack of a good night's sleep & Combined with question 24 \\
\hline 30 & Fighting for air & Omitted (low impact score) \\
\hline 31 & Range of activities & Included in 4 standardized activities \\
\hline 32 & Activities in general & Included in 4 standardized activities \\
\hline
\end{tabular}




\section{Appendix 2: Mini Asthma Quality of Life Questionnaire (MiniAQLQ)@)}

Please complete all questions by circling the number that best describes how you have been during the last 2 weeks as a result of your asthma.

In general, how much of the time during the last 2 weeks did you:

1. Feel SHORT OF BREATH

$\mathrm{S}$ as a result of your asthma?

2. Feel bothered by or have to

En avoid DUST in the environment?

3. Feel FRUSTRATED as a result of your

Em asthma?

4. Feel bothered by COUGHING?

5. Feel AFRAID OF NOT HAVING YOUR

Em ASTHMA MEDICATION AVAILABLE?

6. Experience a feeling of CHEST TIGHT-

S. NESS or CHEST HEAVINESS?

7. Feel bothered by or have to avoid CIGA-

En RETTE SMOKE in the environment?

8. Have DIFFICULTY GETTING A GOOD

$\mathrm{S}$ NIGHT'S SLEEP as a result of your asthma?

9. Feel CONCERNED ABOUT HAVING

Em ASTHMA?

10. Experience a WHEEZE in your chest? $\mathrm{S}$

11. Feel bothered by or have to avoid going

En outside because of WEATHER OR AIR POLLUTION?

\begin{tabular}{|c|c|c|c|c|c|c|}
\hline $\begin{array}{l}\text { All of the } \\
\text { time }\end{array}$ & $\begin{array}{l}\text { Most of } \\
\text { the Time }\end{array}$ & $\begin{array}{l}\text { A Good } \\
\text { Bit of the } \\
\text { Time }\end{array}$ & $\begin{array}{l}\text { Some of } \\
\text { the Time }\end{array}$ & $\begin{array}{l}\text { A Little } \\
\text { of the } \\
\text { Time }\end{array}$ & $\begin{array}{l}\text { Hardly } \\
\text { Any of } \\
\text { the Time }\end{array}$ & $\begin{array}{l}\text { None } \\
\text { of the } \\
\text { Time }\end{array}$ \\
\hline 1 & 2 & 3 & 4 & 5 & 6 & 7 \\
\hline 1 & 2 & 3 & 4 & 5 & 6 & 7 \\
\hline 1 & 2 & 3 & 4 & 5 & 6 & 7 \\
\hline 1 & 2 & 3 & 4 & 5 & 6 & 7 \\
\hline 1 & 2 & 3 & 4 & 5 & 6 & 7 \\
\hline 1 & 2 & 3 & 4 & 5 & 6 & 7 \\
\hline 1 & 2 & 3 & 4 & 5 & 6 & 7 \\
\hline 1 & 2 & 3 & 4 & 5 & 6 & 7 \\
\hline 1 & 2 & 3 & 4 & 5 & 6 & 7 \\
\hline 1 & 2 & 3 & 4 & 5 & 6 & 7 \\
\hline 1 & 2 & 3 & 4 & 5 & 6 & 7 \\
\hline
\end{tabular}

How limited have you been during the last 2 weeks doing these activities as a result of your asthma?

12. STRENUOUS ACTIVITIES

A (such as hurrying, exercising, running up stairs, sports)

13. MODERATE ACTIVITIES

A (such as walking, housework, gardening, shopping, climbing stairs)

14. SOCIAL ACTIVITIES (such as talking,

A playing with pets/children, visiting friends/relatives)

15. WORK-RELATED ACTIVITIES*

A (tasks you have to do at work)

$\begin{array}{ccccccc}\begin{array}{c}\text { Totally } \\ \text { Limited } \\ 1\end{array} & \begin{array}{c}\text { Extremely } \\ \text { Limited } \\ 2\end{array} & \begin{array}{c}\text { Very } \\ \text { Limited } \\ 3\end{array} & \begin{array}{c}\text { Moderate } \\ \text { Limitation }\end{array} & \begin{array}{c}\text { Some } \\ \text { Limitation }\end{array} & \begin{array}{c}\text { A Little } \\ \text { Limitation }\end{array} & \begin{array}{c}\text { Not at all } \\ \text { Limited }\end{array} \\ 1 & 2 & 3 & 4 & 5 & 6 & 7 \\ 1 & 2 & 3 & 4 & 5 & 6 & 7 \\ 1 & 2 & 3 & 4 & 5 & 6 & 7\end{array}$

*If you are not employed or self-employed, these should be tasks you have to do most days.

S: symptoms; En: environment; Em: emotions; A: activities.

(C) The MiniAQLQ is copyrighted. It may not be modified, translated or sold (paper or software) without the permission of Elizabeth Juniper.

\section{References}

1. Juniper EF, Guyatt GH, Epstein RS, Ferrie PJ, Jaeschke R, Hiller TK. Evaluation of impairment of health-related quality of life in asthma: development of a questionnaire for use in clinical trials. Thorax 1992; 47: 76-83.

2. Juniper EF, Guyatt GH, Ferrie PJ, Griffith LE. Measuring quality of life in asthma. Am Rev Respir Dis 1993; 147: 832-838.

3. Rutten-van Molken MPMH, Clusters F, Van Doorslaer EKA, et al. Comparison of performance of four instruments in evaluating the effects of salmeterol on asthma quality of life. Eur Respir J 1995; 8: 888-898.
4. Rowe BH, Oxman AD. Performance of an asthma quality of life questionnaire in an outpatient setting. Am Rev Respir Dis 1993; 148: 675-681.

5. Leidy NK, Coughlin C. Psychometric performance of the Asthma Quality of Life Questionnaire in a US sample. Qual Life Res 1998; 7: 127-134.

6. Sanjuas C, Alonso J, Sanchis J, et al. The quality of life questionnaire with asthma patients; the Spanish version of the Asthma Quality of Life Questionnaire. Archivos de Bronconeumologia 1995; 31: 219-226.

7. Coste J, Guillemin F, Pouchet J, Fermanian J. Methodological approaches to shortening composite measurement scales. J Clin Epidemiol 1997; 50: 247-252. 
8. Juniper EF, Johnston PR, Borkhoff CM, Guyatt GH, Boulet LP, Haukioja A. Quality of life in asthma clinical trials: comparison of salmeterol and salbutamol. $\mathrm{Am} \mathrm{J}$ Respir Crit Care Med 1995; 151: 66-70.

9. Juniper EF, Buist AS, Cox F, Ferrie PJ, King DR Validation of the standardized version of the Asthma Quality of Life Questionnaire. Chest 1999; (in press).

10. Juniper EF, Guyatt GH, Streiner DL, King DR. Clinical impact versus factor analysis for quality of life questionnaire construction. J Clin Epidemiol 1997; 50: 233-238.

11. Juniper EF, O'Byrne PM, Guyatt GH, Ferrie PJ, King D. Development and validation of a questionnaire to manage asthma control. Eur Respir J 1999; (in press).

12. Stewart AL, Hays R, Ware JE. The MOS short-form general health survey. Reliability and validity in a patient population. Med Care 1988; 26: 724-732.
13. Bousquet J, Knani J, Dhivert $\mathrm{H}$, et al. Quality of life in asthma. 1. Internal consistency and validity of the SF-36 questionnaire. Am J Respir Crit Care Med 1994; 149: 371-375.

14. Guyatt GH, Kirshner B, Jaeschke R. Measuring health status: what are the necessary measurement properties? $J$ Clin Epidemiol 1992; 45: 1341-1345.

15. Guyatt GH, Walter S, Norman G. Measuring change over time: assessing the usefulness of evaluative instruments. $J$ Chron Dis 1987; 40: 171-178.

16. Juniper EF, Guyatt GH, Willan A, Grifflth LE. Determining a minimal important change in a disease-specific quality of life questionnaire. J Clin Epidemiol 1994; 47 : 81-87.

17. Fayers PM, Hand DJ. Factor analysis, causal indicators and quality of life. Qual Life Res 1997; 6: 139-150. 